\title{
Social Development (Excerpts from Her 2004 Oral History)
}

\author{
Gloria Davis
}

I did my anthropological research in Indonesia between 1972 and 1974. I happened to work on the movement of Balinese to central Sulawesi, a part of the Indonesian transmigration program, which, in fact, after a few years is what led directly to my being hired by the Bank. I taught at Yale for three years. While I was teaching, a person came up after my lecture, and said, "The World Bank wants you."

I have to admit I didn't even know what the World Bank was. I had a general notion, but nothing specific. To make a long story short, World Bank President Robert McNamara had been to Indonesia and had committed a billion dollars to the Indonesians to expand the Indonesian transmigration program, which he regarded as a very important mechanism for poverty alleviation.

So, in 1978, I agreed to go for six months. I took six months of leave from Yale and went to the Bank to work with a newly-established group under Robert Sadov, which was called Transmigration and Land Settlement. It was focused on Indonesia. And that's the way I got to the Bank.

My first mission in Indonesia was for ten weeks. For the team, it was very helpful to have an anthropologist who knew a lot about the sending areas, Java and Bali. I knew those areas very well, understood a little of both local languages and also spoke Indonesian, so I could tell them a lot about what the farmers were saying about what they could and couldn't expect. When you're using a translator, you always get the official version, like being told that everybody got 1.2 tons of rice. But when you actually ask them how long they could feed their families for and things like that, you get very different answers.

My agriculture colleagues were enormously supportive of me because they wanted to know what I knew. They also wanted to teach me a lot about what they

Gloria Davis was the first Director of Social Development in the World Bank.

This essay is derived from Gloria Davis's 2004 oral history interview. There are no changes of substance, but the editors have made editorial changes (such as sentence breaks, re-sequencing etc.) to conform to written copy. The full interview can be found at https://oralhistory.

worldbank.org/person/davis-gloria 
knew about agriculture. We'd go out with the world's most famous rubber processing specialist or bull specialist or things like that. So I was also learning a lot about technology and what could be introduced and what couldn't be introduced and so forth.

Gradually, I became a mission leader. I want to stress that I had a long and very profitable apprenticeship. For three years people were teaching me how to work in the Bank. They were teaching me the importance of the economic analysis. I learned how to do economic analysis.

My career wouldn't have been the same if I hadn't had that experience. So two things that I felt, and I continued to feel during my period as a manager is that social scientists needed to be integrated into teams, and that they needed to have a very broad knowledge of the objectives that the Bank teams had in order to be helpful to them Later on, when I was the Director of Social Development, I tried every six months to have instruction courses on the Bank project cycle because I felt that they were being isolated from the real activity of the Bank, which was making loans for agricultural activities which were benefiting, we hoped, the smallholders.

In July 1987, Dr. Davis was promoted to unit chief, and then became division chief of the Environment and Social Division in the Asia Technical Department.

During that period, the Bank's regional environmental units all added social scientists. And by the end of that time, there was the expectation that in projects with significant environmental impact those impacts would be addressed, and that social issues needed to be handled. So we had moved quite a way. The next stage of that would be the time when the macro issues become the predominant issues.

We began to see in the Cold War period an alignment between U.S. interests in keeping leaders of countries in my area-[Ferdinand] Marcos, Suharto-in power because they were pro-development, because they were pro-Western, and because they could be counted on as allies. But they would also become these nucleuses of patronage and corruption and so forth. So there was a sort of a whole new constellation of issues that were emerging that were bigger than what the social scientists were used to but also not being addressed at all by the economists.

And another shift that happened at that time (which is just an organizational one, but it accounts for this anomaly of having the social development people in the Environment Department) was that Michael Cernea was debating about whether he could be more effective in agriculture and rural development, which did not give him an overview of other sectors, or whether he should move to the Environment Department. And he decided at that point that he would move and he would become an adviser to the environment director-as I mentioned, it changed-on social issues.

I actually moved first, with a mandate to deal with social issues in an environmental context. We focused on land tenure, social forestry, the impacts of irrigation, agricultural revolution, all of these environmentally-related social issues. We did not yet have a mandate to deal with social issues in general. To give another example, Shelton Davis eventually moved into the division which I headed to bring the indigenous people's agenda, which had been mostly in the Latin America Region at that time, to a more central level to see what could be done with people who had traditional ways and traditional cultures in other regions. 
I later moved to the Central Environment Department. Initially, I was dealing with natural resources management issues. We agreed, under Andrew Steer, on a reorganization where there would be one unit that explicitly dealt with pollution, one on natural resources, and then one on social.

About this time, Ismail Serageldin came into the picture, with a passion for social issues. I can't overemphasize how influential he was in also shaping and influencing the direction of the Bank during this sort of transition period in how we approached social issues.

I think Narmada was a critical watershed. The Bank had commissioned its first independent report, which was the [Bradford] Morse Report. And the 1992 Morse Report was very critical of the Bank. In particular, it criticized the Bank for failing to fully plan for the resettlement of people.

The Morse Report is important for two reasons. First, it led to the 1994 Bankwide resettlement report by Michael Cernea, which had a lasting impact on the Bank. But the second is that it led directly to the Inspection Panel. The Inspection Panel has had a very profound effect on the Bank in terms of keeping it honest and, in fact, in some cases terrorizing staff about the variety of issues which might be encountered in a particular project.

The resettlement report, which was orchestrated by Michael Cernea, reviewed all of the resettlement projects that the Bank had been involved in and found that we had been associated with the resettlement of 2 million people. It was quite an extraordinary revelation to most people. As a result of this report, the Bank then required that any project that had poor resettlement implementation develop an action plan to address those issues. So this resettlement report was not only a critique of a Bank set of projects, but something that built into it after it came out a mechanism for resolution. Those action plans considerably improved the quality of resettlement implementation. Again, this was at the urging and with the advocacy of Michael Cernea, and that was very important.

It's fair to say that resettlement was sort of the flagship or keystone policy for the entire social work at that time. And it was an important entry point for other kinds of social impact assessment. Although Michael and people who assisted him who have since become very senior social scientists in the Bank (Scott Guggenheim, Bill Partridge), a number of these people concluded that the Bank's policies had had an important impact that significantly improved resettlement, which had been a very informal activity in the past.

The reason this is important is because this is the only place where we had a formal policy. So it reinforced for those people, who, as I say, became the nucleus of the social development family, the importance of having a policy, having it on the books, and having a mechanism for external scrutiny that could say whether or not the policy was being appropriately applied.

By this time- this is probably in 1992 to 1994 - there was for the first time a critical mass of social scientists in the Bank who were working in the different regions and at the center. Those of us who had kind of come up through the environment channel, so to speak, and also observing the weight of the resettlement policy, we wanted a broader social impact. Assessment policy, for projects, the 
emphasis was initially on identifying adverse impacts and avoiding, minimizing or mitigating them. But by 1992-1994, we also realized that there was a very important positive role to play in ensuring that social impact assessment was linked to participation, that it involved participatory processes, that we talk directly to affected people, and that we were able to introduce elements into projects that would improve their effectiveness in terms of the people who were intended to benefit.

Now, we weren't alone. If we look around, the Bank was one of many institutions trying to formalize policies that dealt with social impact assessment. We were about a decade behind. The approach to environmental impact assessment had been formalized in the early to mid-1980s. The approach to social impact assessment was being formalized, whether we got a policy or not, in the early to mid-1990s. During this period, although the policy itself was not on the books, actually every region in the Bank began formal social impact assessment, sometimes in parallel with environmental impact assessment. But there was a lot of resistance to formalizing this policy at the level of the Bank. People were concerned that it was too broad, it was too specific, and that it would be too onerous to actually apply.

James Wolfensohn' as arrival in 1995 became the watershed for the way in which we approach social issues. I don't think any of us could have anticipated the impact it would have. What happened is that when Jim Wolfensohn came to the Bank, Michael Cernea approached him very early in his tenure and told him that he was a sociologist. I remember Michael saying that Wolfensohn said he didn't know there were sociologists in the Bank. Michael urged Mr. Wolfensohn to consider much more broadly how social factors were taken into account in the work of the Bank. And Wolfensohn agreed. He came in with an emphasis on sort of human impacts, human values and so on, and he felt that these needed to be much more mainstreamed within the Bank. Michael Cernea had written a book called Putting People First, but I think it was the social development report that brought that home in the Bank as a part of Bank policy or a part of Bank mainstream thinking.

Wolfensohn passed his wish for a broader agenda along to his senior management. It was agreed that there would be a task force would prepare a report on social development in the Bank. Somewhat unexpectedly, it would be half economists and half social scientists. It was chaired, not (as we might have originally thought) by Michael Cernea, but by Javed Burki, who was a senior vice president in the Bank at the time but also one who had very humanistic values and a very broad view. Although an economist himself, his view of economics certainly embraced the kind of social and equity concerns that the rest of us shared. So he was, in my view, a very good choice to lead this.

The emphasis of the group - which was not fully achieved, I have to tell youwas to bring economists and social scientists together and to get them to decide how social factors should be incorporated. Not just social impacts, but also broad social factors, political factors, issues related to equity and so forth. The mandate was to get these two sometimes polarized groups, the macro economists and some of the micro economists, to speak to the social scientists.

To be perfectly honest, the social scientists had everything to gain from this initiative and the economists who were involved in the group were willing 
participants but also felt they had a lot to lose. They felt they were already dealing with social issues and social impacts. Joanne Salop, who eventually had the thankless job of writing the final report in conjunction with a senior economist and myself, said that we often talked past one another, and that was true. The economists felt that the social scientists were too particularistic, too interested in differences to be able to recommend universal laws or approaches. The social scientists felt the economists were too universal, too generalized, to appreciate the particulars of what was going on in countries and to adapt and tailor projects and programs to the realities of what was happening on the ground.

The one thing that I think gradually brought some consensus was that there was a grudging acceptance of participation as a test for both groups. We had been promoting participation through the NGO group and the social group in the Environment Department, but people recognized that it was a test of economic policy. If people were not satisfied, if the impacts of economic policies were not positive in a relatively short amount of time on poor people, there would not be political support for these kinds of activities.

There was a sub-group on conflict. People already working on conflict were able to show that 16 of the poorest 20 countries in the world were in conflict; that this was no longer an isolated phenomenon; that it wasn't post-war reconstruction of the sort we'd had at the end of World War II; that these were civil conflicts, often conflicts between governments and their people; and that dealing with conflict was going to be an important element of poverty. There were a number of substantive issuessocial capital, conflict, culture-that were addressed by the subcommittees, as well as the overall concern that, as we said at the beginning of the report, the success of development is measured by its impact on people.

The report came out. It was an extreme compromise. There was an original report to which the social team subscribed and a kind of a compromise report written, as I said, between the three of us, based on the input of all of the others. It was a middleof-the-road report. Its importance was that even this kind of discussion and dissent led everybody to recognize - no, or at least some people, and certainly Ismail-to conclude that there needed to be a formal structure that recognized the importance of social development. We also had some important advocates in very high places in the Bank, so that when the Strategic Compact was prepared there was money included for advancing social development.

I was the social scientist who had provided the major input into the Presidential Report, though not necessarily the workings of the committee. Among the others there was a major advocate for the creation of a network particularly to advance the social development agenda. As a matter of fact, if it hadn't been for Ismail Serageldin and his strong views on that, I think there wouldn't have been a social development network. But having created one, when management went looking for a leader who was relatively senior and had been involved for a time, I was fortunate to have been selected.

From the outset, I was mainly interested in setting up the network and handing it over to others, and this is in fact what we did over the next sort of three to five years. We tried to develop a structure, an institutional structure, and leaders that could take 
over from some of we old hands that had been doing it at that point for about 20 years.

Like other networks, our social development board consisted of a representative from each of the regions, someone who normally headed a social development division or at least a unit in that particular region. Collectively, the board was interested initially in determining what were the areas of work to which we should devote our limited resources and then building a record of results on the ground Since each region had somewhat different social problems, it was often very difficult to get agreement on what should be the emphasis within a newly-emerging agenda.

But in the end, and after a lot of sort of trial and error, we could see that there were several issues that really characterized what we did. Within about five years of the founding of the network-it seems long, but it involved a lot of work-there was a document issued on poverty and social impact assessment. I think it was important for a couple of reasons. One is that the economists in the Poverty Reduction and Economic Management Network, worked closely with the social development team to develop that document. It basically that gives pointers on tools and perspectives for evaluating whether economy-wide policies are having the desired impacts on the poor.

The other area that was already pretty far along when the network was formed is the subject of participation. That had an interesting evolution. In the earliest stages, participation really meant consultation; that is to say that if you were trying to figure out what was going on, you would ask people. Now, they didn't get a say in the outcome, but they could provide important feedback. This type of consultation was institutionalized both in the social impact assessment process and also in the environmental impact assessment process, which became much more "participatory" over time. But with the publication of the participation report, which was a very participatory process led by Aubrey Williams - 20 different groups and so forththe people who were advocating participation came to see this more and more as control over decisions and resources on the part of people who might be affected by them. This changed perspective played into a lot of things that we did later onsocial capital, understanding the institutions of the poor and so on.

The culmination of that within the 1997 to 2002, was Deepa Narayan's work on voices of the poor. This was a kind of listening to something like 60,000 people in different countries. It was done in preparation for the poverty report in the year 2000-2001. It was criticized by some for its lack of empirical rigor, but it was absolutely overpowering in terms of what poor people were saying about themselves.

It was a very, very important document. It had a big influence on Wolfensohn. It had a big influence, I think, on the poverty people who were working on the poverty report. So this was one place where interests really came together, this very strong thrust toward participation and the sort of change over time to being more empowering and getting people more involved in decisions.

This emphasis on participation, empowerment and community-driven development, which is a derivative of that, also gave both socially-oriented economists and social scientists an opportunity to actually be involved in the design and 
implementation of projects. With the advent of a whole series of projects related to empowerment, civic engagement and so on, there was much more latitude for people who were sympathetic to these objectives to be involved in the design and implementation of projects.

Another sort of thrust of our work was also coming together. I was very, very interested in local-level institutions-in fact, it's sort of what I had done my dissertation on, and I had been waiting to get back to it-because it had seemed evident to me even 20 years before that communities with strong institutions were more likely to be resilient and they could move forward faster than communities within cultures or even the same culture that didn't have strong institutions. In about 1995 we once again got some funds from our friends in Norway for a study of locallevel institutions that eventually became the work on which social capital and community-driven development was based.

We had originally hoped to get six countries but only three of them were completed. There were some surprising findings. NGOs in terms of advocacy groups and social service groups and so on, were not well represented at the village level in any of these studies. Religious groups were often more important than we anticipated, particularly in societies that weren't particularly religious. Obviously, every society has its own religious beliefs and constructs and so on, but even where we didn't see religion as a major motivating force, religious organizations often provided a sort of a network for both protecting vulnerable groups and also for reaching out to local-level groups.

But village organization was really important. All villages were organized; they all had headmen. Where those people were positive and proactive and where their objectives were linked to the objectives of the community, there was a lot more sense of trust and confidence and people working together than where the head men were corrupt and taking, you know-as you can imagine. It seems self-evident. But it did lead to a series of hypotheses about how we might try to reach communities more directly and how we might try to circumvent elites that had been co- opting resources in the past and, you know, set up organizations at the community level that could actually pay attention to the community interests.

There are many, many good examples of social capital initiatives, some of which emerged from this, some of which had independent origins. And in my paper I have cited the ones that Scott Guggenheim has done. I think he has done the most to develop the idea about how you can circumvent elites, how you can reduce corruption at the community level by making things very transparent, by making people accountable for how resources are being spent. He even has components in all of his projects for NGOs and newspapermen to go to villages and discuss with villagers whether the money is being used appropriately, to cut through this kind of tradition of elite co-option, let's say, of all of these resources. So he has done a lot of both substantive and research-related work on that, and that moved very effectively.

Now, it was interesting - because as we moved more and more toward economywide lending, we also were arguing that there needed to be a component of the Bank's lending program that went directly to people and didn't go into the sort of national coffers and never saw the bottom. And Hans Binswanger was instrumental 
in bringing that view. It wasn't his view initially, but he brought that view to Wolfensohn's attention, and Wolfensohn agreed that a significant portion of Bank lending should be directed to the community level. This led to, as it often does a lot of renaming of projects that weren't exactly community-driven, but it also was a tremendous impetus to having a certain number of projects that were communitydriven. And the aggregate total of community-based projects is now very large, something around 6 billion dollars. A lot of Bank resources now go to the community level.

There was also another thrust of the participation agenda that I think has promise and is beginning to show it, which is on social accountability. There are a number of countries now where the team has worked with the government-or perhaps in NGOs in some cases where that's acceptable - to put in place mechanisms for the public to assess public institutions.

The Philippine report card is one of them. Two thousand or five thousand people are surveyed about their attitudes toward, let's say, the education department, the postal department, the health resources. The institutions are then graded publicly, in the newspaper. This has had a tremendous impact. Institutions that are getting Ds, Cs even, are publicly exposed in these sort of report card activities, and we have seen some change.

I've seen other examples of social accountability, even, for example, in education projects where parents are now encouraged to give an assessment of the schools, and then those are aggregated to see which schools appear to be doing better and which are doing worse in the subjective impression of the people. Now, those seem like commonplace things, opinion polling and so forth, in the United States, but here we're trying to formalize them for use in developing countries.

In speaking about local-level institutions, we also felt that we needed to move local-level institutions from the local level to the state level because it was clear that state institutions were the glue that held countries together. If we were going to do program lending, understanding accountability, transparency and the relationship to the functioning of the institutions of the state was really important.

This class of work was also directly relevant to our interest in conflict. When states fail, what you have is conflict, and often civil conflict. And unlike the earlier wars which had been between countries and were ideologically-driven, what the Bank was seeing in these very poor countries it was dealing with was civil war within countries, often based around ethnicity. States had been ineffective in sharing the wealth, in giving disenfranchised groups reason to think that they should be confident that the state would be acting in their interests and so on.

So, the conflict program also became part of the social agenda. We took the same series of steps that we had in a number of other areas to try to institutionalize and give a higher profile to that agenda. First, we wrote a paper showing how important conflict was in the poverty agenda. When there was agreement that conflict was a high-priority area, we were able to assemble a group, first at the regional vice president level but then at the level of operations officers when it became more routinized. They met on a regular basis to decide what should be done about the conflict agenda, what DEC [Development Economics] would be doing. 
Then, finally, there was one part of the social agenda that I actually was quite sympathetic to and thought had promise, but our group was very divided. This was on poverty and culture. In the end, that agenda has been very dispersed. The tensions were around the definition of culture.

The social development group had been given the responsibility for follow-up on culture, but it contributed to the problem by defining it a little bit differently and wanting to work more with the cultural assets of the poor. One program worked with radio and local languages because radio stations in many countries were only in the national language and not accessible to poor people. Another example might be about traditional artisanal activities and crafts and how they might be strengthened. But it was a much more kind of locally-based interest in culture.

The social development team as a whole felt that culture was a universal and ought to be integrated into everything that we were doing. It wasn't about historical monuments or even about artisanal activities. If you would talk to the people in the Eastern Europe region, culture, you know, underpinned conflict, economic reform, all-there were a whole series of things. They were the ones that were most interested in cultural monuments and cultural heritage in the sort of traditional sense because it was so closely linked to identity and the dissolution of the Russian Federation. But if you went to Latin America, there was a different definition of culture that was smaller, more locally-based, probably reflected traditional practices, for example, indigenous people, where the issue was how the way of life of an entire group could be to some extent preserved and not simply exterminated in the process of development. So there were these sort of contending views on the nature of an agenda that was focused on culture.

And, finally, the Board made it very clear that certainly the Bank needed to be culturally sensitive in all aspects of its work and anything that we were doing or that others were doing that would make staff more sensitive or managers more sensitive was appropriate; that, of course, if work actually had economic benefits for the poor, that using cultural, artisanal activities (to refer to the one we just talked about) were appropriate; but the Bank really had no role, unless it had very clear economic benefits - and there were other institutions much better able to do this, in the UN, for example-in protecting and preserving cultural monuments.

And I have to say this was a very confusing activity. I mean, it's pretty easy to clarify what was going on, but nobody gave up on their own position. And eventually when resources became more and more constrained, the diversity of opinion around this meant that this program was being supported largely with external resources, mainly from the Italians, and became more and more constrained within the Bank context. But I do expect culture to re-emerge as an important issue.

One thing that surprised me was that it was much easier to promote social impact assessment than environmental impact assessment. And that's true because countries could immediately see-not that they were dying to do this as a requirement of the World Bank - but that they could see the logic of the fact that they couldn't alienate the people that were going to have to support them politically in carrying out projects. So whether or not they had a sort of poverty objective, they could understand that it was important to figure out whether people were going to be 
harmed, what could be done about that, whether there are opportunities for improving their welfare and so forth.

If I look at myself and think of a person who came in with the idea that they would be going to Indonesia and speaking Indonesian to farmers and trying to improve projects who became someone who has had to deal with issues as large as economic equity, or large-scale conflict, for example, there's obviously a lot of room in the Bank for a social person to grow and evolve. And I think that there's no question among the applied social scientists that hardly any of us would ever return to an academic environment. Virtually all of the people who are in the social development community want to have an impact on the ground.

As I mentioned at the outset, I taught at Yale, which is a wonderful experience. The students are all unbelievably bright, but you realize that, over time, they are the ones that are going to have an impact. You're having an impact on them, and they should have an impact on others, but it's very indirect. Development is not like that. You're working with poor people, and if what you're doing makes a difference, the life of those specific poor people could actually be improved. And that is very, very, very rewarding.

Gloria Davis was the first anthropologist hired by the World Bank. She specialized in Southeast Asia, receiving her Ph.D. from Stanford University in 1975 with a dissertation on Parigi: A Social History of the Balinese Movement to Central Sulawesi, 1907-1934. She then taught anthropology for three years at Yale University. In 1978 Davis joined the World Bank's Indonesia Transmigration and Land Settlement Program, where she became part of the team assessing the Bank's support for transmigration projects in Indonesia. This led to the publication of the major report, Indonesia Transmigration Program Review, in 1981. In 1984 Davis became the senior operations office in the agriculture division of the East Asia and Pacific Region. She participated in various missions, often to Indonesia but also to Fiji in 1984. During this period she lead the review of the entire Indonesia transmigration sector, culminating in a major report, Indonesia Transmigration Sector Review, in 1986. Following the general reorganization of the World Bank in 1987, Davis became the chief of the Environment Division of the Asia Technical Department. In 1990 she wrote another major study, Indonesia: Sustainable Development of Forests, Land and Water. She became chief of the Social Policy and Resettlement Division in the Environment Department in 1993 and director of the Social Development Department from 1997 until 2000. Davis retired from the Bank in 2000 but continued to serve as a consultant until 2004. Gloria Davis was born in 1943 in Minneapolis, Minnesota.

Open Access This chapter is licensed under the terms of the Creative Commons Attribution 4.0 International License (http://creativecommons.org/licenses/by/4.0/), which permits use, sharing, adaptation, distribution and reproduction in any medium or format, as long as you give appropriate credit to the original author(s) and the source, provide a link to the Creative Commons license and indicate if changes were made.

The images or other third party material in this chapter are included in the chapter's Creative Commons license, unless indicated otherwise in a credit line to the material. If material is not included in the chapter's Creative Commons license and your intended use is not permitted by statutory regulation or exceeds the permitted use, you will need to obtain permission directly from the copyright holder.

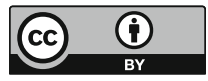

